\title{
A COMPARATIVE STUDY OF MATING STRATEGIES \\ IN TWO SPECIES OF PHILANTHUS \\ (HYMENOPTERA: SPHECIDAE)
}

\author{
Howard E. Evans \\ Kevin M. O'Neill \\ Department of Zoology and Entomology \\ Colorado State University
}

\section{Objectives}

Our work on the reproductive biology of Philanthus pulcher and $\mathrm{P}$. zebratus in Jackson Hole in 1980 was a continuation of a study which had three major objectives. The first was to determine the relationship between female and male activity patterns. As in other species with extensive female-contributed and no male-contributed parental investment, females are a resource necessary for reproductive success of males. Thus, the activity of females in time and space should be an important parameter affecting the evolution of male mating strategies. Our work in this area is being combined with data we have gathered elsewhere on other species of Philanthus ( $0^{\prime} \mathrm{Neill}$ and Evans, unpublished). The second objective was to determine what characteristic of males was important in determining reproductive success and the form of the mating strategy. Since our preliminary data on Philanthus indicated that body size may be the most important variable affecting male reproductive success, we concentrated on this aspect of male biology. This report will focus on our results in this area. The third objective was to determine the role of male-produced sex pheromones in the mating system.

\section{Methods}

Methods consisted mainly of direct observation of marked individuals of known size. Head width of males and females in the field was measured to the nearest $0.1 \mathrm{~mm}$ with a VWR Scientific Products micrometer. Head width is highly correlated with body weight in Philanthus basilaris ( $0^{\prime} \mathrm{Neill}$, unpublished). Censuses were taken of males involved in mating activities.

\section{Results}

The mating strategy of males of Philanthus zebratus in Jackson Hole has been previously described (Evans and 0 Neill, 1978). It is unique among the Sphecidae in that males swarm (i.e., make "high-flights") above the nesting area, intercepting females as they make flights to and from their nests. Since studying males in this population for the first time in 1977 we have also discovered territorial males in the population. These males set up territories immediately adjacent to the nesting area and scent mark the plants around the perch in order to attract females for mating purposes. 
Males of $\underline{P}$. pulcher set up territories along the Snake River outside of the nesting area of the females. Observations of mating behavior support the contention that the males scent mark the plants in the territory in order to attract females. Males display a behavior ("abdomen dragging") which has been previously suggested to function in depositing a pheromone on plant stems (Gwynne, 1978; 0'Neill, 1979). Mating is initiated when a female flies upwind and lands on the territory. The male then mounts and mates with the female, who remains passive for the duration of copulation. We have tentatively identified the chemical structure of the contents of the male mandibular glands, with the aid of Dr. J.0. Schmidt of the University of Georgia. The chemicals are consistent with the types of chemicals used as sex pheromones by many Lepidoptera. Unfortunately, the chemical analysis was not completed in time to conduct field bioassays this summer. We plan to continue this work in 1981 .

We were most successful in our investigation of the role of size variation in the mating systems of the two species of the Philanthus. A summary of the results is as follows. (In some cases the data for 1979 and 1980 are combined. All measurements are of head width.)

1) Sexual dimorphism. In both species there is distinct sexual size dimorphism, females being larger than males on the average. This is in contrast to most vertebrate species with polygynous mating systems and intense male-male aggressive competition (e.g., Shine, 1978, 1979). Females of $P$. zebratus and $P$. pulcher have mean head widths and 3.81 $\mathrm{mm}$ and $2.73 \mathrm{~mm}$ respectively while males average $3.24 \mathrm{~mm}$ and $2.33 \mathrm{~mm}$. In both species, males are also more variable in size than females. There is also a well-defined color dimorphism in both species.

2) Size and alternative strategies in Philanthus zebratus. As mentioned above, males of $\underline{P}$. zebratus in this population display two different mating strategies. $\bar{s}$. Our work in 1979 indicated that smaller males tended to display territorial behavior while larger males made high flights above the nesting area. We continued this aspect of the investigation in 1980 in order to determine if this was indeed true and to ascertain whether there was individual behavioral flexibility with respect to the form of behavior displayed. Combined data for the two years show that territorial males had a mean head size of $3.06 \mathrm{~mm}$ (S.D. $=0.26 \mathrm{~mm}$ ) and that high-flying males had a mean size of $3.36 \mathrm{~mm}$ (S.D. $=0.20 \mathrm{~mm}$; difference significant, t-test, $P<0.001$ ). (Figure 1) of 95 males observed undertaking one of the two strategies, only 3 males were observed to both be territorial and to make high-flights at different times. All three of these males were above average in size. Although less than $3 \%$ of the males displayed both behaviors, this is enough to allow us to conduct that there is not a fixed polymorphism for mating behavior.

3) Aggressive interactions in $P$. pulcher. In this species 68 aggressive interactions between males of known size were observed. Ninetyseven percent of the interactions between males of different size $(\mathrm{N}=$ 63) ended with the larger male expelling the smaller male from the territory. Males which won aggressive interactions were significantly 


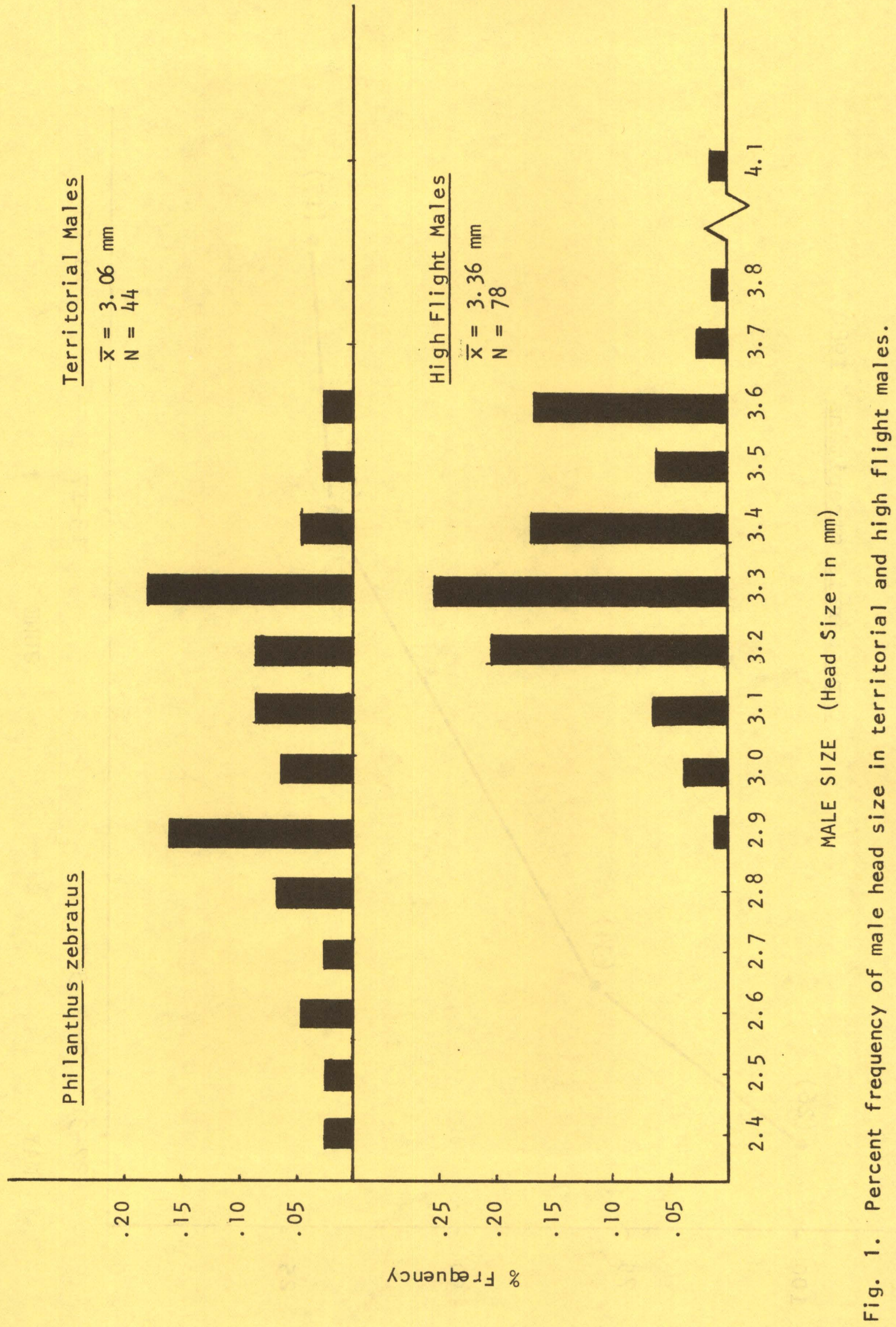


larger (mean=2.51 mm) than males which lost (mean=2.22 mm; t-test, $P<$ $0.001)$.

4) Territorial males. While only $30 \%$ of the males had a head width of $2.5 \mathrm{~mm}$ or greater, they occupied $72 \%$ of the territories censused in $1980(\mathrm{~N}=190)$. We have data that indicate that territorial males obtain the vast majority of matings ( 11 of 12 observed).

5) Removal experiments. The effect of size was substantiated by removing males of known size from the territories and observing which males replaced them as residents. The replacing males were also removed, this being continued until no males occupied the territories. In all 19 cases, the first male occupying the territory after removal of the original resident was smaller than $(\mathrm{N}=18)$ or the same size as $(\mathrm{N}=1)$ the original male. The mean size of the original males, including those not replaced, was $2.54 \mathrm{~mm}(\mathrm{~N}=27)$ while the replacing males had a mean size of $2.28 \mathrm{~mm}(\mathrm{~N}=38$; difference significant, t-test, $\mathrm{P}<$ $0.001)$. It appears that there is a large pool of non-territorial males that are smaller in average body size than the males holding the territories.

\section{Conclusions:}

Given the superiority of large males of $P$. pulcher in intrasexual competition it is difficult to explain why there is so much size variability in the population. It may be that smaller males are less subject to predation than large males, but this is unlikely since our results with territorial $P$. basilaris ( $0^{\prime} N e i l l$, unpublished) show the opposite to be true. It is possible that smaller males undertake a "satellite male" strategy, attempting to intercept a female before she reaches a territory or before a large male detects a female's presence on his territory. Small males also quickly occupy abandoned territories and attempt to forcibly copulate with females in the nesting area early in the day.

Territoriality and scent marking are common male behaviors in the subfamily Philanthinae, to which these two species belong. It is therefore valid to assume that it is an ancestral character and that the high-flight strategy of male $P$. zebratus has evolved more recently. Our work on the role of body $\overline{s i z e}$ in male success in aggressive encounters (in P. pulcher and P. basilaris) makes it clear that large males enjoy higher fitness than smaller males undertaking the same strategy. Why, then, have large males of $\underline{P}$. zebratus abondoned the territorial strategy and adopted a swarming strategy? It must be that relative to territorial males, swarming males are more successful. Since females probably mate only once in their lifetime, any mating behavior which allows a male to intercept a receptive female before she can mate with a territorial male will be selected for. Larger males may be better at the high-flight strategy either because they are stronger fliers or because their size makes them better able to overpower the large females as they grapple in mid air.

In both species, because of the decreased competitive ability of 
smaller males they are selected to behave in a way which minimizes their inevitable disadvantage. As Dawkins (1980) puts it, "they make the best of a bad job" in a conditional strategy based on body size.

In our future work we plan to relate female parental investment to sexual dimorphism, size variability, and mating strategies. Evidence from other Hymenoptera suggests that body size is determined largely by parental investment.

\section{Acknowledgements}

We thank Dr. Kenneth Diem and the staff of the University of Wyoming NPS Research Center for their hospitality during the course of the study and the National Park Service for their financial support.

Dawkins, R. 1980. Good strategy or evolutionarily stable strategy? In: Sooiobiology: Beyond Nature/Nuture? G. Barlow and J. Silverberg eds. Westview Press, Inc., Boulder, Colorado.

Evan s, H. E. and K. M. $O^{\prime} \mathrm{Ne} i 11$. 1978. Alternative mating strategies in the digger wasp Philanthus zebratus. Proc. Natl. Acad. Sci. $75(4): 1901-1093$.

Gwynne, D. T. 1978. Male territoriality in the bumblebee wolf, Philanthus bicinctus Mickel (Hymenoptera: Sphecidae): Observations on the behavior of individual males. Z. Tierpsychol. 47:89-103.

0'Neill, K. M. 1979. Territorial behavior in males of Philanthus psyche (Hymenoptera: Sphecidae). Psyche. 86(1):19-43.

Shine, R. 1978. Sexual size dimorphism and male combat in snakes. 0ecologia (Ber1.) 33:261-268.

- 1979. Sexual selection and sexual dimorphism in the amphibia. Copeia 1979:297-306. 